DOI 10.37882/2223-2982.2020.04-2.26

\title{
КОНЦЕПТ «СОЧУВСТВИЕ» В ЯЗЫКОВОЙ КАРТИНЕ МИРА (НА МАТЕРИАЛЕ РУССКОГО И АНГЛИЙСКОГО ЯЗЫКОВ)
}

\section{«EMPATHY» CONCEPT IN THE LANGUAGE PICTURE OF THE WORLD (BASED ON THE MATERIAL OF RUSSIAN AND ENGLISH LANGUAGES)}

\section{Z. Minasyan}

Summary: This scientific article attempts to compare the concept of "sympathy» in Russian and English on the material of literary sources and dictionary articles. As a result of the research, it was proved for the first time that the words used are synonyms of the concept «sympathy» Express the emotional state in different languages based on the national culture. The theoretical and practical significance of systematization of the main provisions of the sections of linguistics that study the issues of emotional concepts is revealed and justified.

Keywords: concept, empathy, emotions, culture, mentality, lexical and semantic field.
Минасян Зинаида Тиграновна

Ассистент, Российская академия народного хозяйства и государственной службы minasyan-zt@ranepa.ru

Аннотация: В данной научной статье предпринята попытка сопоставления концепта «сочувствие» в русском и английском языках на материале литературных источников и словарных статей.

В результате проведенного исследования впервые доказано, что используемые слова-синонимы концепта «сочувствие» выражают эмоциональное состояние в разных языках на основе национальной культуры.

Выявлена и обоснована теоретическая и практическая значимость систематизации основных положений разделов лингвистики, изучающих вопросы эмоциональных концептов.

Ключевые слова: концепт, сочувствие, эмоции, культура, менталитет, лексико-семантическое поле.
$\mathrm{B}$ се языки мира имеют свою специфику, которая обусловлена особенностями национального мышления, поэтому на протяжении многих лет взаимосвязь языка и культуры подвергается исследованию ученых-лингвистов.

В последнее время возрос интерес к таким дисциплинам, которые изучают национальный язык, связывая его с мышлением, культурой, в чем прослеживается тенденция к сохранению самобытности национальных особенностей. В связи с этим становится актуальным изучение концепта как ментальной особенности языкознания.

В данной статье будут рассмотрены основополагающие лексические средства реализации концепта «сочувствие», которые составляют области в концептосфере представленного для анализа материала русского и английского языков. Концепт, выделенный в данных областях, подвергается детальному изучению.

Концепт «сочувствие» является лингвокультурным концептом, который формируется взаимодействием трех составляющих понятийной, образной и ценностной. Л.И. Миллер, И.А. Стернин рассматривают концепт «сочувствие» как единицу художественной картины мира, которая запечатлена в художественном тексте. Основу исследования составили труды отечественных и зарубежных ученых в области лингвистики эмоций (В.В. Жура, В.И. Шаховский, L. Jaeger), труды, посвященные изучению когнитивной лингвистики (М. Джонсон, И.А. Стернин, Д. Лакофф)[4,с.165].

Данное исследование посвящено концепту «сочувствие» в русском национальном сознании в сопоставлении с концептом «sympathy» в сознании носителей английского языка.

Сфера эмоций является благоприятным полем для исследования, поскольку именно в ней наиболее полно выражаются особенности национального сознания. Сочувствие как базовая эмоция, передающая психо-эмоциональные состояния человека, и концепт, проявляющий себя в любой культуре, становится основополагающим объектом для исследования и выявления национальной специфики. Именно в этом состоит актуальность данного исследования.

В настоящее время следует отметить приобретение важности сопоставительного изучения различных концептов эмоций в контексте динамичного развития, на которое оказывает влияние национальной культуры[6,с.620]. Проблема исследования заключается в том, чтобы провести сопоставительный анализ концепта «сочувствие» на материалах русского и английского языков.

Цель исследования состоит в комплексном анализе концепта «сочувствие» как предмета языкознания, т.е. в 
рассмотрении концепта в лингвостилистическом и культурологическом аспектах на материале английского и русского языков.

Для реализации цели исследования поставлен ряд задач:

1. описать структуру концепта «сочувствие»;

2. исследовать особенности концепта «сочувствие» в современном языкознании;

3. провести анализ лексико-семантических полей в концепте «сочувствие» на материале русского и английского языков.

Научная новизна работы заключается в том, что впервые комплексно исследован концепт «сочувствие» с точки зрения лингвистических особенностей на материале русского и английского языков.

Теоретическая значимость работы состоит в систематизации основных положений разделов лингвистики, изучающих вопросы языковой репрезентации эмоциональных концептов.

Практическая значимость работы состоит в том, что материалы исследования могут быть использованы в курсах теории и практики перевода, лексикологии английского и русского языков, сопоставительной лексикологии русского и английского языков.

В работе применены следующие методы: метод случайной выборки, описательно-аналитический метод использован для систематизации лексико-семантических полей в концепте «сочувствие»; сравнительно-сопоставительный метод использован для определения национальных особенностей концепта «сочувствие».

Для выявления языковых средств передачи концепта «сочувствие» нами составлен подробный алгоритм действий:

1. Для выявления языковой репрезентации концепта используются словарные дефиниции слованаименования концепта «сочувствие».

2. Методом случайной выборки выявляются способы реализации концепта «сочувствие».

3. Выбранные слова и словосочетания анализируются на предмет тематики и частотности.

4. Составляется модель языковой репрезентации концепта «сочувствие» в английском и русском языках.

В ходе исследования были изучены словарные значения соответствующих концептам лексем, эмпирической базой для этого послужили различные толковые словари русского и английского языков:

- толковые словари русского языка под редакцией С.И. Ожегова, Д.Н. Ушакова, Т.Ф. Ефремова;
- словари английского языка: Dictionary of the English Language by Houghton Mifflin, Kernerman Webster's College Dictionary и Oxford dictionary.

Изученные словарные статьи были обобщены, значения лексем классифицированы, что позволило проанализировать сходства и различия в понимании лексем в русском и английском языках, а, следовательно, и выявить концептуальные различия.

Концепт «сочувствие» является лингвокультурным концептом, который формируется взаимодействием трех составляющих понятийной, образной и ценностной.

Репрезентантами концепта «сочувствие» являются существительные, которые приобретают дополнительные семантические признаки: отзывчивость, переживание, сострадание, жалость, сожаление.

Материалы исследования позволяет выявить семантическую структуру концепта. Значительное увеличение количества ассоциатов у концепта «сочувствие» появляется за счет его репрезентации в русском языке, что является отражением русской ментальности.

Характерной чертой изучаемого концепта можно считать языковую избирательность[11,с.688]. В русском языке сочувствие подобно награде, приводящее в замешательство говорящего:

- почтить сочувствием;

- смущать сочувствием;

Следует отметить, что сочувствие сравнивается с даром:

\section{сочувствие дается в благодать}

При этом сочувствие сравнивается такими главными ценностями, как любовь:

Любовь, участие, забота.

Как показывают различные исследования, филологов и психологов, англичане не любят злоупотреблять эмоциональными разговорными формулами[9,с.170]. Поэтому в качестве примера для исследования концепта взят роман Д.Остина «Эмма»/ Jane Austen «Emma», который акцентирует внимание на том, что, несмотря на видимую замкнутость и отсутствие внешних проявлений эмоций, англичане способны к сочувствию и готовы оказать помощь в любой ситуации.

Matrimony, as the origin of change, was always disagreeable; and he was by no means yet reconciled to his own daughter's marrying, nor could ever speak of her but with compassion, though it had been entirely a match of affection, when he was now obliged to part with Miss Taylor 
too/Супружество, как изначальная причина перемен, всегда внушало ему неприязнь; он далеко еще не смирился с замужеством родной дочери, отзывался о ней не иначе как с состраданием, хотя та вышла замуж единственно по любви, и вот его уже принуждали расстаться также с мисс Тейлор.

Для того чтобы полностью раскрыть суть концепта «сочувствие», необходимо выявить элементы концепта и обозначить их взаимосвязи. Начинать анализ концепта следует с одноименной лексемы. Рассмотрим словарные дефиниции в русских и английских толковых словарях.

На основе данных толкований выделяем следующие компоненты, которые отражены в таблице.

Рассмотрим словарные определение слова «sympathy», английский репрезентант концепта «сочувствие».

Проанализировав материал, написанный выше, мы можем сказать, что когнитивная модель концепта «сочувствие» в русских и английских словарях складывается, в первую очередь, из качеств, относящихся к отзывчивости и состраданию[7,с.114].

Словарные определения слова «сочувствие», английского слова «sympathy», а также синонимов исследуемого концепта.

Рассмотрим значение русского слова.

Таблица 1

\section{Словарное определение слова «сочувствие»}

\begin{tabular}{|c|c|}
\hline Значение слова «Сочувствие» & Словари \\
\hline $\begin{array}{l}\text { Отзывчивое отношение к чужому } \\
\text { чувству, сострадание }\end{array}$ & $\begin{array}{l}\text { С.И.Ушаков. Толковый словарь } \\
\text { русского языка Ушакова. } 2012\end{array}$ \\
\hline $\begin{array}{l}\text { 0тзывчивое, участливое отношение } \\
\text { к переживаниям, несчастью других }\end{array}$ & $\begin{array}{l}\text { С.И. Ожегов } \\
\text { Толковый словарь русского язы- } \\
\text { ка }\end{array}$ \\
\hline $\begin{array}{l}\text { Отзывчивое, участливое отношение } \\
\text { к чьему-л. горю, переживаниям; со- } \\
\text { страдание. } \\
\text { устар. Благосклонное, благоже- } \\
\text { лательное отношение к кому-л., } \\
\text { чему-л.; }\end{array}$ & $\begin{array}{l}\text { Т.Ф. Ефремова Толковый словарь } \\
\text { русского языка. }\end{array}$ \\
\hline
\end{tabular}

Проанализировав значение слова «сочувствие», мы можем утверждать, слово имеет одну общую семантику «переживание» и «сострадание», т.е. «сочувствие», по нашему мнению, соотносится с понятием «переживание».

Рассмотрим толкование слова «sympathy» в английских словарях.
Таблица 2

\section{Словарное определение слова «sympathy»}

\begin{tabular}{|c|c|}
\hline Значение слова «sympathy» & Словари \\
\hline $\begin{array}{l}\text { 1. симпатия, расположение } \\
\text { 2. взаимное понимание; родство } \\
\text { душ, солидарность } \\
\text { 3. сочувствие, сострадание } \\
\text { 4. соответствие; гармония }\end{array}$ & $\begin{array}{l}\text { Dictionary of the English Language } \\
\text { by Houghton Mifflin, }\end{array}$ \\
\hline 1.Сочувствие, симпатия & $\begin{array}{l}\text { Kernerman Webster's College } \\
\text { Dictionary и Oxford dictionary }\end{array}$ \\
\hline
\end{tabular}

Таким образом, мы обосновали мысль о том, что значение как русского, так и английского слова «сочувствие» имеет одну семантику, формально круг значения лексем совпадает.

Необходимо отметить, что проводимый контекстуальный анализ, а также описание ассоциативного концептуального поля, в основе которого исследование словарей-тезаурусов. Данный вопрос подтверждает расширение представления о составе интерпретационного поля.

В русском языке концепт «сочувствие» приобретает дополнительные семантические признаки, которые следует выделить в пять групп:
1. отзывчивость;
2. переживание;
3. сострадание;
4. жалость.
5. сожаление

Как в русском, так и в английском языках имеют место синонимические ряды ядерных лексем, представляющих концепт «сочувствие».

Для наглядности хотелось бы сопоставить схемы синонимов, представленные в концепте.

Понятие «сочувствие» складывается из следующего синонимического ряда:

\section{Сочувствие - переживание - сострадание - жа- лость-сожаление}

B английском языке лексемы «Empathy» можно классифицировать следующим образом: Empathy experience - compassion - pity-regret.

Проведенный сопоставительный анализ позволил выделить как сходства, так и отличия в значениях синонимов ядерных лексем концепта «сочувствие» в ан- 
глийском и русском языках.

Анализ синонимов подтверждает, что концепт «сочувствие» является абстрактным понятием. Кроме того, исследуемый концепт тесно связан с другими такими же абстрактными понятиями.

Таким образом, несмотря на то, что сочувствие базовое эмоциональное чувство, и этот концепт так или иначе проявляет себя в любой культуре, нельзя не отметить отсутствие идентичности концепта «сочувствие» в русском национальном сознании и национальном сознании носителей английского языка.

В заключении можно сделать вывод, что концепт «сочувствие» является абстрактным понятием, сочетаемым с такими же понятиями. Концепт не только отражает не только эмоциональную сферу человека, но и затрагивает ному и модель поведения носителей языка.

Данное суждение позволяет сделать следующие вы- воды относительно концепта «сочувствие» в языковой картине мира носителей английского и русского языков:

1. Концепт сочувствие в сознании носителей английского и русского языков обнаруживает ряд сходств. В первую очередь сочувствие - это качество, относящееся к отзывчивости и состраданию;

2. Английский концепт позволяет выявить установившуюся связь между чувствами, эмоциями и ощущениями человека, вызванными различными повседневными ситуациями, которые определенным образом воздействуют на него.

3. Для русского человека проявление сочувствия является, прежде всего, внутренним переживанием. Однако для представителей англоязычной культуры душевное переживание менее актуально, чем внешнее проявление чувств.

Исследованная в работе вариативность эмоционального концепта «сочувствие» на материалах русского и английского языков открывает перспективы для его сопоставительного изучения.

\section{ЛИТЕРАТУРА}

1. Болдырев Н.Н. Концепт и значение слова//Методологические проблемы когнитивной лингвистики: научное издание. Воронеж, 2001. с. $25-45$.

2. Воркачев С.Г. Ex Pluribus Unum: лингвокультурный концепт как синтезное образование // Вестник Российского университета дружбы народов. Серия: Лингвистика. 2016. Т. 20. № 2. с. 17-30.

3. Вендина, Т.И. Введение в языкознание: Учебник для академического бакалавриата / Т.И. Вендина. - Люберцы: Юрайт, 2016. - 333 с.

4. Даниленко, В.П. Введение в языкознание: Курс лекций / В.П. Даниленко. - М.: Флинта, 2015. - 288 с.

5. Даниленко, В.П. Общее языкознание и история языкознания: курс лекций / В.П. Даниленко. - М.: Флинта, 2016. - 272 с.

6. Демьянков В.3. Термин «концепт» как элемент терминологической культуры//Язык как материал смысла: Сборник статей в честь академика Н. Ю. Шведовой / Отв. ред. М.В. Ляпон. - М.: Издательский центр «Азбуковник», 2007 (РАН: Институт русского языка им. В.В. Виноградова) - с. 606-622.

7. Овчинникова Н.В., Столярова Л.Г., Тарасова М.В. Сравнительно сопоставительный анализ концепта «сочувствие» в английском, французском и русском языках // Современные проблемы развития фундаментальных и прикладных наук: материалы III международной научно-практической конф. (25 апреля 2016 г.). Praha, (zech Republic, 2016. Том 3. с. 114-122.

8. Слышкин Г.Г. Лингвокультурные концепты и метаконцепты. - Волгоград: «Перемена», 2004. - 340 с.

9. Скребнев Ю. М. Очерки английской стилистики. - М.: Высшая школа, $1994-240$ с.

10. Текст культуры и культура текста: Материалы IV Международного педагогического форума (Сочи, 16-17 октября 2017 года) [Электронный ресурс] / Ред. кол.: Л.А. Вербицкая, С.И. Богданов, О.Е. Дроздова и др. — СПб.: РОПРЯЛ, 2017. - 755 с. 